\title{
Figura y semblanza de Ignacio Ellacuría
}

\author{
HÉCTOR SAMOUR \\ Universidad Centroamericana José Simeón Cañas
}

Resumen: Esta semblanza de Ignacio Ellacuría, resalta no sólo su trabajo de conciencia crítica de la realidad salvadoreña en un momento especialmente difícil de la historia del país, sino su papel protagónico en el proceso de paz, que fue consecuencia de su talante intelectual y humano. Reconocido teólogo de la liberación, Ellacuría también elaboró un proyecto de filosofía liberadora, riguroso y bien fundamentado, que constituye una contribución relevante a la tradición latinoamericana. Destaca en este ensayo, su contribución a pensar la ideologización como proceso negador de la realidad que solo puede ser develada a partir de un pensamiento y una praxis liberadora. Dicha liberación se realiza en el ámbito de la realidad histórica, que este pensador concibe de carácter abierta, no sujeta a determinismos o leyes inmutables. Esta filosofía liberadora la denomina una filosofía cristiana, no porque obedezca fines doctrinales, sino porque está marcada por la cruz como esperanza y liberación.

Abstract: This biographical sketch of Ignacio Ellacuría underlines both his work as critical consciousness of Salvadoran reality in a especially difficult momento in the history of that country and his protagonic role in the peace process, that was a consequence of his intelectual and human stature. A recognized theologian of liberation, Ellacuria also elaborated a rigorous project for a Philosophy of Liberation that constitute a relevant contribution to that Latin American tradition of thought. This essay highlights his contribution to think ideologization as a process that negates a reality that can only be unveiled through emancipating thought and practice. Such an emancipation is achieved in the field of historical reality, that this thinker understands as an open ended process, not subjetct to determinisms or immutable laws. This Philosophy is termed a Christian Philosophy, not because it follows doctrinal purposes, but because it carries the symbol of the cross, as hope and liberation.

\section{Palabras claves}

Teología de la liberación, filosofía de la liberación, realidad histórica, liberación, praxis liberadora, ideología, ideologización, mal común.

\section{Keywords}

Theology of Liberation, Philosophy of Liberation, Historical Reality, Liberation, Liberating Praxis, Ideology, Ideologization, Common Evil 


\section{Aspectos relevantes de la biografía de Ignacio Ellacuría}

Ignacio Ellacuría es un intelectual reconocido internacionalmente, no solo por sus contribuciones teóricas originales a la teología de la liberación y a la construcción de un pensamiento filosófico crítico y liberador de cara a la realidad latinoamericana, sino también por su rol en la búsqueda de una solución negociada al conflicto armado interno en El Salvador durante la década de los ochenta.

Ignacio Ellacuría fue un sacerdote jesuita, español de nacimiento pero nacionalizado como salvadoreño. Llegó a El Salvador en 1949 y permaneció allí hasta su muerte, en 1989. Pudo haberse quedado en España o trabajar en las mejores universidades del mundo, pero optó por quedarse en El Salvador, impactado por la injusticia estructural, la extrema pobreza y la exclusión social de la mayoría de la población, así como por la represión de los gobiernos militares de la época, baluartes últimos en la defensa de los intereses económicos de los grupos oligárquicos que se habían enriquecido a partir del cultivo y la exportación del café, desde finales del siglo XIX.

Ellacuría fue parte del grupo de jesuitas que fueron asesinados por el ejército salvadoreño en 1989 en su residencia del campus universitario. Su legado intelectual, moral y político todavía continúa inspirando la misión liberadora de la universidad de la que formaban parte, y actualmente es una referencia ineludible de la práctica social cotidiana de mucha gente y de la acción de movimientos sociales en El Salvador y en otros países latinoamericanos, así como también de una amplia producción intelectual de académicos de diversas disciplinas en América Latina, Estados Unidos y Europa.

El 15 de noviembre de 1989, el alto mando de la Fuerza Armada de El Salvador ordenó el asesinato de Ignacio Ellacuría y de otros jesuitas. En las primeras horas del 16 de noviembre, miembros del Ilamado batallón Atlacatl, un batallón élite del ejército salvadoreño entrenado por asesores militares estadounidenses, entraron a las instalaciones de la Universidad Centroamericana José Simeón Cañas (UCA) y asesinaron a Ellacuría, Ignacio Martín-Baró, Segundo Montes, Juan Ramón Moreno, Amando López, Joaquín López y López y a sus colaboradoras, Julia Elba Ramos y a su hija Celina. Los soldados habían recibido órdenes de matar a Ellacuría y no dejar testigos. Los detalles de los asesinatos y el posterior encubrimiento han sido cuidadosamente documentados por el informe de la Comisión de la Verdad de las Naciones Unidas, publicado en 1993 (Doggett, 1994; Whitfield, 1998). Actualmente 
está pendiente en España, en la Audiencia Nacional, la apertura del juicio contra los autores intelectuales de los asesinatos, que depende de la extradición de uno de los oficiales que participó en la decisión del alto mando de aquella época, y que actualmente se encuentra detenido en Estados Unidos.

Esta masacre vino a culminar una serie de amenazas a muerte y difamaciones contra el equipo de jesuitas y laicos liderado por Ellacuría, incluyendo atentados con bombas en los edificios y a la imprenta de la universidad jesuita, desde mediados de los años setenta en El Salvador. Hay que mencionar también que Ellacuría y otros miembros de su equipo tuvieron que salir al exilio dos veces, a mediados de 1977 y a finales de 1980, cuando recibieron información confiable de que iban a ser asesinados en forma inmediata por parte de los escuadrones de la muerte, vinculados al ejército salvadoreño.

Por eso es razonable suponer que su asesinato se había decidido desde hace mucho tiempo por parte de los grupos de la derecha económica y militar, pero cuya ejecución solo dependía del momento y las condiciones propicias para materializarlo. Momento y condiciones que los militares encontraron justamente en esas fechas, en el contexto de una gran ofensiva militar llevada cabo por los grupos guerrilleros que alcanzó la capital salvadoreña, San Salvador, y otros grandes núcleos urbanos, en el marco de la guerra civil que azotaba el país centroamericano desde 1980.

Paradójicamente, estos asesinatos aceleraron la creación de condiciones políticas para la solución negociada del conflicto interno, al deslegitimarse la posición del ejército salvadoreño a nivel nacional e internacional, lo cual minó seriamente la estrategia contrainsurgente ejecutada por el ejército durante toda la década de los ochenta en El Salvador, y que fue diseñada, apoyada y financiada con miles de millones de dólares por parte del gobierno de los Estados Unidos, con el fin de aniquilar a las fuerzas insurgentes.

La masacre de la UCA provocó la condena de la comunidad internacional, la suspensión de la ayuda militar y del apoyo político estadounidense del cual gozaba el ejército. El Congreso de los Estados Unidos se negó a seguir financiando la guerra en El Salvador, forzando a los militares a aceptar el proceso de diálogo-negociación, que eventualmente condujo a una drástica reducción del poder que tradicionalmente habían tenido las fuerzas armadas dentro de la sociedad salvadoreña.

En el momento de su muerte, Ellacuría era rector de la universidad, vicerrector de proyección 
social, jefe del departamento de filosofía y editor de muchas de sus publicaciones académicas, especialmente de la revista Estudios Centroamericanos (ECA), cuyas publicaciones de aquella época son todavía ahora una referencia documental obligada para los investigadores que quieran conocer crítica y rigurosamente la historia de El Salvador en las décadas de 1970 y de 1980, más allá de lo que narra la historia oficial.

De sus 22 años de trabajo en la UCA, en sus últimos 10 años como rector, Ellacuría había jugado un rol prominente en organizar y orientar todo el poder institucional de la universidad, a través de su investigación, docencia y proyección social, y de todas sus publicaciones, hacia el análisis de las causas de la pobreza, la exclusión y la opresión en El Salvador. Además, Ellacuría tuvo una importante presencia pública en los medios de comunicación denunciando las causas estructurales del conflicto armado, los fraudes electorales, la represión militar contra las organizaciones populares y los agentes de las comunidades eclesiales de base, el cierre de las vías pacíficas para acceder al control del poder político por parte de la oposición al régimen militar, y la violación de los derechos humanos perpetrada por los dos principales bandos en pugna, pero especialmente la cometida sistemáticamente por el ejército salvadoreño, en la represión y en la ejecución de masacres de miles de pobladores en las comunidades campesinas que estaban dentro de las zonas de combate.

Junto a esta labor de denuncia y crítica, Ellacuría también se involucró tenazmente en la búsqueda de la solución negociada del conflicto armado. Su voz y presencia pública, sus diálogos con representantes de las fuerzas gubernamentales e insurgentes, su apoyo a la realización de un debate nacional por la paz en el que participaran organizaciones de la sociedad civil no alineadas con alguna de las partes contendientes, entre otras acciones personales que emprendió, estaban orientadas fundamentalmente al objetivo último de la paz. En sus últimos dos años de vida buscó organizar a grandes segmentos de la población para que presionaran a las partes en lucha a que dialogaran y negociaran la finalización de la guerra, que buscaran acuerdos que, primeramente, minimizaran los daños que provocaban las acciones militares en la población civil y que, después, produjeran una serie de acciones que sentaran las bases para un proceso genuino de desmilitarización y democratización de la sociedad salvadoreña.

En esta línea hay que entender su tesis de la "tercera fuerza", que la lanzó públicamente en el año de 1986. Ellacuría sostenía que a pesar de que ambas partes se habían reestructurado y fortalecido para 
conseguir sus objetivos políticomilitares, ninguna de ellas había conseguido debilitar a la otra; por el contrario, se habían potenciado. Si esto era así, era necesario -sostenía Ellacuría-, hacer algo cualitativamente nuevo que no fuera en la línea de robustecer a una de las partes en conflicto. Su propuesta se basaba en el hecho real de que la mayor parte de la población y un buen grupo de importantes fuerzas sociales deseaban una solución distinta a la de la guerra. ¿Por qué no aprovechar la fuerza de la sociedad para obligar a concluir la guerra, para definir medidas provisionales mientras no se finalice y para encontrar puntos fundamentales de acuerdo para empezar a resolver las causas estructurales que dieron origen al conflicto? Ellacuría no estaba proponiendo un tercer partido político que entrara en la contienda ni mucho menos una "tercera vía", sino que estaba apelando a la fuerza de la sociedad civil, de los sindicatos, de las organizaciones no gubernamentales, de las iglesias, de la pequeña y mediana empresa y de otras organizaciones sociales, con el fin de que, en un proceso negociador, esta fuerza de la sociedad ejerciera presión para finalizar el conflicto armado, defender los intereses de las mayorías populares y democratizar el país.

Posteriormente, entre 1990 y 1991, cuando ambas partes en conflicto empezaron a caer en la cuenta no solo del empate militar, sino también de la presión abrumadora del pueblo salvadoreño a favor de la paz y de la necesidad de un acuerdo negociado, la tesis de la tercera fuerza de Ellacuría empezó a cobrar realidad y mostraba la racionalidad de su propuesta, que en el momento que él la formuló, no fue valorada adecuadamente por las fuerzas contendientes. Al final, el tiempo le dio la razón. Los acuerdos de paz que pusieron fin al conflicto salvadoreño fueron firmados en enero de 1992.

Los militares y los grupos oligárquicos de la época creyeron que Ellacuría era un guerrillero. El alto mando del ejército que ordenó su asesinato, lo hizo creyéndolo eso, un promotor de la violencia. Pero no era así. Ellacuría era un hombre que quería y que buscaba la paz. No solo buscó que grandes segmentos de la sociedad se movilizaran por la paz, sino que también intentó construir puentes para que terminara una guerra empantanada y productora no solo de una violencia caduca, sino también de más pobreza y de exclusión social, que irónicamente era lo que perseguían erradicar los dirigentes insurgentes, en la guerra civil entonces en marcha.

Ellacuría planteaba que un sistema radicalmente violento era el que no permitía vivir en forma humana, digna, a la mayoría de personas y a las comunidades. Es la 
"violencia primera", la "violencia radical" o "institucional" como la Ilamó la Conferencia de Obispos
Latinoamericanos de Medellín, en 1968:

... es la injusticia estructural, la cual mantiene violentamente -a través de estructuras económicas, sociales, políticas y culturales- a la mayor parte de la población en situación de permanente violación de sus derechos humanos. (Ellacuría, p. 169)

Los obispos en Medellín también decían que a esta violencia primera, seguía la "violencia segunda", la violencia insurreccional, la que respondía el pueblo organizado con armas y revolución, contra la opresión y la exclusión.

Ellacuría no aceptaba esta violencia segunda e incluso condenaba tajantemente sus formas terroristas, pero decía que había que considerar a la violencia institucional (o estructural) como causa última de la otra. Planteaba que podíamos intervenir en una historia abierta donde ya hay situaciones hechas pero en las que podemos actuar con voluntad y decisión.

Pero además, Medellín señalaba que hay una tercera violencia, que es la del Estado que acalla a los que no lo aceptan, a los disidentes. Es la violencia represiva. Esta violencia, la violencia represiva, fue la que asesinó al rector, a sus compañeros y compañeras, con una tecnología terrorista que trató de aniquilar a su crítico y su legado.
Ignacio Ellacuría y su equipo de colaboradores, jesuitas y laicos, tuvieron un compromiso firme con la resolución de los conflictos de El Salvador y Centroamérica y sus alcances los sitúan en el grupo de trabajadores por la paz y el desarrollo social en sus países, como Gandhi, Martin Luther King y Mandela. Sus proyectos personales, sus compromisos misioneros, sus trayectorias individuales, su conocimiento y su experiencia se articularon en una estrategia contra la desigualdad de la sociedad salvadoreña, buscando la promoción del ser humano y su liberación, el conocimiento transformador de la realidad, la reconciliación nacional y la causa revolucionaria de la paz. Su obra en favor de la gente en distintos campos de la vida social es lo que los hace perdurar en el tiempo.

Lo destacable de Ignacio Ellacuría era que a la par que se involucraba en la dinámica socio-política salvadoreña, ejercía su cargo de rector y realizaba sus tareas de 
profesor, también producía intelectualmente en el campo de la teoría política, la teoría universitaria, la teología y la filosofía. A los que vivían con él les admiraba su capacidad de trabajo y de poder dedicarse con tanto acierto e intensidad a ocupaciones tan variadas y que exigían tanta dedicación.

Ellacuría fue y es conocido principalmente como uno de los principales representantes de la teología de la liberación. Sin embargo, él paso las dos últimas décadas de su vida elaborando las bases de un proyecto de filosofía liberadora de cara a la realidad histórica latinoamericana, fundamentalmente sobre la base del pensamiento filosófico de Xavier Zubiri. El último trabajo que dejó al momento de su muerte, su libro Filosofía de la realidad histórica, que no pudo publicar en vida, es un texto de más de quinientas páginas, inacabado, y sometido a varias revisiones y correcciones por parte del mismo Ellacuría, que dieron lugar a diferentes versiones del texto, que él comenzó a redactar en 1975 (Samour, 2003). La última versión fue publicada póstumamente en 1990 en El Salvador por la editorial de la UCA, y en España, en 1991, por la editorial Trotta (ahora agotado). (Ellacuría, 1990/1991).

En los años posteriores a su muerte hasta la fecha, un buen número de académicos e intelectuales han recolectado y estudiado sus textos filosóficos, muchos de ellos inéditos en la vida del autor, y han reconstruido su pensamiento filosófico, mostrando que Ellacuría tenía no solo una teología, sino también una filosofía propia, bien elaborada, estructurada y fundamentada, la cual constituye una relevante contribución a la tradición latinoamericana de pensamiento crítico y liberador.

De todo lo dicho antes, quisiera destacar algunos temas de suma relevancia del legado de Ignacio Ellacuría.

\subsection{Una universidad distinta}

Sin la UCA no es pensable ese hombre multidimensional, o mejor, transdimensional, que fue Ignacio Ellacuría. El filósofo, el teólogo, el humanista, el analista de la realidad socio-política, el sacerdote, el hombre de paz, el intelectual, el hombre de la praxis histórica, no puede ser comprendido sin su universidad. Él conoció, vivió y apreció muchas universidades de distintas partes del mundo, pero la UCA fue su espacio formativo, su hábitat creativo y su fortaleza, no su refugio, sino su exposición a los mundos de riesgo, sean esos políticos, intelectuales, académicos, de pobreza, de exclusión e incluso militares. Es decir a mundos históricos que comprendió y que buscó transformar. Desde su universidad, Ellacuría transformó realidades, personas, grupos, instituciones, 
mentalidades, políticos, hombres y mujeres de todos los sectores. Hasta se cambió constantemente a sí mismo.

Para Ellacuría, la universidad no era un campo de batalla, un lugar para campañas políticas, una retaguardia para la acción de los políticos, pero tampoco era un espacio apolítico y neutral, organizado únicamente para formar profesionales, según las demandas del mercado laboral. La UCA era un espacio para la crítica de la realidad social e histórica, pero también de elaboración de propuestas concretas y viables para el logro de una nueva vida. Era un espacio para ejercer una crítica con el fin de introducir racionalidad en el proceso sociopolítico, teniendo como objetivo la transformación de la sociedad, de la polis y de los ciudadanos, en la búsqueda del logro de una vida buena, al mejor estilo de la labor socrática, que tanto admiraba (Ellacuría, 2001a, pp. 116ss). Ellacuría sostenía que la injusticia Ileva consigo una carga de irracionalidad, y la irracionalidad es un dato primario de sociedades divididas y contrapuestas como la salvadoreña, caracterizadas por la desigualdad, la pobreza y la exclusión de grandes segmentos de población. Por esa razón, al ser la universidad una institución cuya finalidad es introducir en el cuerpo social el máximo de racionalidad, la situación de esas sociedades exige su intervención, justamente, por su radical situación de irracionalidad.

La universidad, el pensamiento, el saber y la cultura eran para Ellacuría la forma de comprender y abrir nuevas perspectivas de futuro fundadas en la inteligencia, en resultados de la investigación socio-histórica, en el desarrollo de las ciencias, de las técnicas, de la teología, de la filosofía y su interminable búsqueda de la verdad, para la plena humanización y felicidad de los seres humanos en una sociedad concreta. Por eso insistió, desde la década de 1970, en constituir una universidad al servicio de la sociedad, acompañando a los pobres y sus luchas en sus reivindicaciones más sentidas, buscando iluminar los caminos que deberían transitar para que pudieran lograr su liberación definitiva (Ellacuría, 1991b).

Se debe construir una cultura liberadora -decía Ellacuría (1999)para no dejar "la historia de un pueblo en las manos exclusivas de los cultivadores políticos del pueblo, de los cultivadores que buscan el poder (supuestamente) para el pueblo, ya no digamos de cultivadores de otro corte político" (p. 60). La cultura de la universidad debe ser una cultura que rompa todo vínculo de dominación, "una cultura que avance hacia una liberación siempre mayor, pero una cultura realmente vivida en cada paso del proceso" (Ibíd.). 
En esta línea, Ellacuría era infatigable, siempre actuando, siempre animando a sus estudiantes, a sus colegas y colaboradores para comprender la realidad nacional y actuar desde la universidad, sin que ésta perdiera su especificidad. Criticaba a las universidades que se convirtieron en corredores y salas de partidos políticos o de organizaciones político-militares desde donde se organizaban manifestaciones y protestas callejeras, en las que su vida académica cotidiana se reducía a la mera reproducción acrítica de ideologías y de panfletos. Pero también criticó a las universidades que se centraban en sí mismas, pretendiendo permanecer ajenas al acontecer social y político, sin tratar de incidir positivamente en el proceso histórico del país, para el logro de una sociedad más justa, más incluyente, y por ende, más libre (Ellacuría, 1999, pp. 55ss). ${ }^{2}$

La universidad que dejó Ellacuría y su equipo es ahora un modelo de centro universitario serio, tanto en lo académico como en la investigación, al servicio de un país y de una región, de un mundo incandescente en forma permanente que nunca dejará de estar en ebullición sociopolítica. En este contexto, la universidad debe volver permanentemente no al pasado, al que Ellacuría ponderaba pero no le rendía culto, sino a la realidad histórica (1990/1991), que funde los distintos tiempos para efectuar acciones, según las posibilidades reales, que lleven a más vida y que permitan ir superando procesualmente la injusticia estructural que abate a las sociedades de los países pobres.

\section{2 La crítica de las ideologizaciones}

Hay que mencionar también al Ellacuría filósofo que en forma rigurosa criticaba las ideologizaciones que ofrecían una imagen distorsionada y falsificadora de la realidad, legitimando y justificando así el estado de cosas presente. Si la universidad debe ser crítica, si la UCA era y debe ser crítica es porque el filósofo Ellacuría era crítico y creativo. En realidad, Ellacuría (1991c) no se oponía a las ideologías; él pensaba que como estructuradoras de ideas, valores y pasiones, son necesarias para las propuestas políticas movilizadoras y juegan un papel fundamental en una praxis liberadora (p. 104). ${ }^{3} \mathrm{~A}$ lo que se oponía era a las ideologizaciones que hacen pasar por real, lo que solo se queda en mera formulación abstracta e ideal, encubriendo y legitimando así el mal común dominante en la sociedad (Samour, 2013).

Las ideologizaciones son fenómenos que representan un obstáculo serio a una praxis liberadora, debido a que están en estrecha vinculación con realidades sociales muy influyentes en la configuración de la conciencia colectiva y de 
las conciencias individuales. Estas ideologizaciones se materializan en las constituciones, en instituciones sociales como el ejército, la familia, las iglesias, las escuelas, las universidades, los partidos políticos y los medios de comunicación, y se difunden a la población por los más diversos canales, provocando que se generen conciencias paralelas apenas interactuantes entre lo que se dice profesar y lo que realmente se ejecuta, o conciencias interactuantes, pero donde solo se permite expresar la realidad en un lenguaje que la idealiza y la justifica, ocultando lo que en realidad es "sucio y deformante" (Ellacuría, 1991c, p. 100). Por eso decía Ellacuría (1991c) que el fenómeno de la ideologización nos enfrenta "con la nada con apariencia de realidad, con la falsedad con apariencia de verdad, con el no ser con apariencia de $\operatorname{ser}^{\prime \prime}$ (p. 101). Es esto justamente lo que hace necesaria la acción negadora de la crítica, que es algo consustancial al genuino quehacer filosófico, para barrer con lo que de "nebuloso" hay en el ámbito de lo ideologizado y posibilitar así la develación de la realidad y poder afirmarla en su fundamento, rompiendo con el "falso fundamento de la falsa realidad que se nos quiere imponer en distintas formas de ideologización" (p. 102).

Ellacuría consideraba esta función crítica de la filosofía como una parte esencial de la "función liberadora de la filosofía" (p. 93), y que valoraba como algo fundamental para iluminar y acompañar críticamente una praxis de liberación, en el sentido de que el ejercicio desideologizador permita vislumbrar, a partir de la crítica de lo existente y de las ideologías que lo legitiman y justifican, nuevos horizontes de transformación de la realidad histórica, a partir de las posibilidades objetivas que se ofrecen en cada situación histórica o en cada época (Ellacuría, 1990/1991, pp. 519ss).

La liberación fue el gran tema y el proyecto de la vida intelectual de Ellacuría. La filosofía, a la cual dedicó toda su vida, era un factor estratégico para criticar, interpretar, iluminar y ofrecer modelos alternativos de sociedad para incidir en la transformación de la realidad histórica centroamericana y latinoamericana. La filosofía era parte de su vida, que se nutría de la realidad y que la utilizaba para ejercer la crítica y la creación. En primer lugar, la crítica contra las ideologizaciones y de todo aquello que en el ámbito de la conciencia colectiva del cuerpo social oculte o deforme la realidad con el fin de justificar y legitimar la injusticia estructural. En segundo lugar, la creación en la producción de teorías y propuestas novedosas, que orienten y acompañen acciones liberadoras, según el contexto y la situación concreta, sobre la base de un análisis muy riguroso y crítico de la realidad socio-histórica. Lejos de convertir 
a la filosofía en una mera práctica profesional o en una mera especulación vacía, abstracta y ahistórica, para Ellacuría era un modo de vida que se transforma en liberadora del sujeto que reflexiona y la construye, ya sea un individuo o una comunidad, si es que se ejerce con autenticidad y rigor intelectual, y se asumen con honestidad las exigencias de la realidad concreta desde la que se filosofa.

En sus escritos políticos se puede apreciar con claridad la aplicación de esta concepción ellacuriana del quehacer filosófico. (Ellacuría, 1991a). En dichos escritos, Ellacuría procedía a un análisis crítico de las políticas económicas, de las estructuras sociales, del Estado, del derecho, del marco constitucional, de las fuerzas armadas, de los procesos electorales, de las ideologías políticas, del conflicto armado. Se trataba de un ejercicio desideologizador, en el que ponía en cuestión los múltiples elementos ideologizados que influían en la configuración de la realidad salvadoreña de la época. Pero a la vez que realizaba esta labor crítica, Ellacuría estaba siempre atento a descubrir posibilidades para la solución a los principales problemas y abrir nuevos caminos para hacer avanzar el proceso salvadoreño, en un equilibrio difícil entre la utopía de la liberación de las mayorías y aquello que era posible en cada fase del proceso.

\section{3 La realidad histórica como ámbito de la liberación}

El filósofo Ellacuría sentía una inmensa pasión por la historia que abarca todo lo real. Pero no buscaba simplemente el dato histórico, hacer mera historiografía convencional, para simplemente describir acontecimientos pasados. Ellacuría buscaba influir en ella, intervenir en la realidad histórica que, desde su concepción filosófica, es una realidad unitaria, abierta, dinámica, que tiene nodos y redes sobre los cuales hay que actuar para modificarla desde sus "goznes estructurales" (2009a, pp. 265ss).

Este acento en lo estructural puede parecer que soslaya lo personal, o que minimiza su importancia, pero lo que hay que entender es que la realización de lo personal no puede concebirse realistamente al margen de lo estructural. La pregunta, entonces, es qué estructuración de la sociedad permite el desarrollo pleno y libre de la persona humana y qué acción personal en la transformación de las estructuras debe ser la de quienes en ella participan. La liberación, para Ellacuría (2009b), se refiere, por consiguiente, tanto a las estructuras como a las personas. El análisis científico de la realidad, por su mismo carácter, lleva a centrar la atención sobre males estructurales y reformas estructurales, pero el análisis filosófico y teológico muestra que las dimensiones 
y las realidades personales son también momentos importantes de las estructuras históricas, con una entidad propia y una relativa autonomía, y que, por tanto, no pueden soslayarse en la tarea histórica de liberación (pp. 282ss). Expresado de otra manera, se puede decir que la acción liberadora debe pretender la liberación y la realización personal, pero esta no se logrará de forma realista si no se enmarca dicha liberación en la construcción de nuevas estructuras que exijan el comportamiento libre y pleno de las personas.

La referencia al carácter estructural de la historia pone en claro la necesidad de la intervención humana, directa o indirecta, para que las estructuras históricas posibiliten la humanización de los seres humanos, una vez que estos las hayan humanizado. La historia, en la visión ellacuriana, no está regida por leyes o esencias inmutables, ni está dirigida por macro-sujetos que la orienten teleológicamente hacia un determinado fin. La historia está dinamizada por la praxis opcional de individuos y de colectivos sociales, sobre la base de las posibilidades reales con las que cuentan en cada situación o en cada época histórica, y nunca está garantizado el éxito de las opciones o decisiones que asuman en un momento determinado, en términos de humanización o personalización (Ellacuría, 1990/1991, p. 520).
De ahí el carácter ambiguo del proceso histórico, que puede humanizar o deshumanizar a los seres humanos. Puede ser principio de libertad, pero también de opresión; puede ser principio de verdad, pero también de mentira y falsedad; puede ser principio de luz, pero también de oscuridad; puede ser, en definitiva, principio de creación de realidad, pero también de obstrucción y de regresión. No hay garantías trascendentales que aseguren el progreso humano en la historia. De ahí que Ellacuría (2009a) insista en la necesidad de preguntarse "en cada caso cuál es la índole del proceso, qué juicio merece, en qué etapa está y cómo se puede colaborar a su marcha" (p. 267), para iluminar y acompañar praxis emancipadoras. Para ello será necesario buscar la explicación más racional y científica posible, no dejándose llevar ni de las apariencias, ni de los prejuicios ideológicos, ni de otro tipo de factores distorsionantes en la captación de la realidad de los hechos.

El punto de partida de los análisis ellacurianos fue la negatividad que se da en la realidad histórica, para desde ahí preguntarse por las posibles soluciones que permitieran irla superando históricamente a través de procesos teóricopraxicos de emancipación, que se configurarían como procesos superadores de la negación, o de negación de la negación, en un sentido 
dialéctico. Frente a las proclamaciones abstractas e ideologizadas del bien común, como un bien general, Ellacuría (2001b) sostenía que lo que en realidad se da es el mal común. El "mal común" es el estado real del mundo en el que la mayoría de la gente está estructuralmente mal por el mismo ordenamiento de las condiciones de vida de ese mundo. Se origina a partir de estructuras injustas que dificultan una vida humana y que, por tanto, deshumanizan a la mayor parte de quienes viven sometidos a ellas, y se plasma en una injusticia institucionalizada en las leyes, costumbres, ideologías, y en el resto de dimensiones de la vida social. Frente al mal común, así definido, surge el bien común como una exigencia negadora de esa injusticia estructural e institucional.

Esto le lleva a Ellacuría a considerar que las elementales exigencias contenidas en el programa de los derechos humanos son, en realidad, una necesidad para posibilitar la actualización histórica del bien común. En la situación determinada por el mal común y en la tensión que ella provoca con el bien común deseado, se fundamenta, para Ellacuría, la exigencia de reclamar los derechos humanos, como un reclamo concreto de la necesidad de hacer realidad el bien o de alcanzar históricamente el bien común. Los derechos humanos, desde la perspectiva del mal común dominante, los muestra como el bien común concreto, que debe ser buscado en la negación superadora del mal común, que es una situación en la que son violados permanente y masivamente los derechos humanos (Senent, 1998).

Una violación así de los derechos humanos que se da en la actual civilización del capital como resultado de la ruptura de la solidaridad del género humano, que lleva a la absolutización del individuo, de la clase social, de la nación o del bloque económico, por encima de todo los demás y de la humanidad misma (Ellacuría, 1992). En este contexto, el liberalismo es la ideología que legitima y justifica esta situación, y da cobertura jurídica y formal a las libertades de las élites ricas y privilegiadas, que procuran a su vez, que no las consigan otros, respecto de ellas, "por sucesivos y más complejos procesos de liberación" (Ellacuría, 1989, p. 161).

\section{4 La tarea intelectual como una forma de vida entregada a la liberación}

En su último escrito filosófico publicado en 1985, "Función liberadora de la filosofía", Ellacuría habló de la constitución de una filosofía liberadora como una filosofía cristiana, no porque dicha filosofía busque poner la reflexión filosófica al servicio de las directrices doctrinales de alguna autoridad eclesiástica o al servicio de lo que se considera una verdad inmutable, 
sino porque pretende instalar su filosofar "en el lugar privilegiado de la verdad de la historia que es la cruz como esperanza y liberación" (Ellacuría, 1991c, p. 61).

Desde el punto de vista cristiano, la cruz como categoría general e histórica simboliza el lugar donde se experimenta la opresión y la muerte de la humanidad, "la crucifixión del pueblo bajo forma de dominación y de explotación". Y en este sentido, no hay duda que la elección de la cruz para encontrar la verdad puede ser paradójica, decía Ellacuría. Sin embargo, contra la sabiduría griega y occidental, "la locura de la cruz" es uno de los lugares dialécticos por antonomasia, "no para negar la sabiduría en general, sino un modo de sabiduría que precisamente está elaborado sea desde los crucificadores activos, sea desde quienes no están interesados por el fenómeno masivo de la crucifixión histórica de la humanidad" (Ellacuría, 1991c, p. 61). Y en la medida en que la filosofía instale su filosofar en la cruz de la historia, el método dialéctico queda fundamentado, según Ellacuría (1991c), ya no como un método lógico ni como un método universal, aplicable a la naturaleza y a la historia, como quiere Hegel, sino como un "método que sigue la historia y que la historia impone a quien la quiera manejar" (p. 61).

Las características históricas de la cruz pueden ser muy distintas según la altura procesual de la realidad histórica y según la situación de los pueblos y de las personas. Pero en la actualidad, y vista la historia desde la realidad de las mayorías populares, decía Ellacuría (1991c) "parece indiscutible que la cruz tiene unos trazos bien precisos, reconocibles inmediatamente por la configuración de los crucificados de la tierra, que son las inmensas mayorías de la humanidad, despojadas de toda figura humana, no en razón de la abundancia y de la dominación, sino en razón de la privación y de la opresión a las que se ven sometidos" (p. 61).

En este sentido, la tesis de la cruz como lugar privilegiado para encontrar la verdad histórica, no significa afirmar, como lo postula Heidegger, que la nada descubre el ser o que desde la nada se hacen creativamente todas las cosas -ex nihilo omne ens qua ens fit-, sino que hay "quien haga de la nada el ser" y que, por lo tanto, el ente no puede salir de la nada, sino que "hay que hacerlo, aunque sea de la nada, esa nada que a nosotros se nos presenta como negación y aun como crucifixión" (Ellacuría, 1991c, p. 61).

En la contribución de Ellacuría al proyecto de una filosofía de la liberación se puede destacar la importancia de su reflexión sobre la praxis histórica, su concepción de la estructura y las fuerzas de la realidad histórica, su interpretación de las 
relaciones entre teoría y praxis, su visión del sujeto de la historia, así como la relevancia de sus ideas sobre la esencial historicidad y politicidad de la filosofía e incluso su idea misma de liberación. Pero su contribución no solo se redujo a estas tesis. Ellacuría vivió lo que inspiraba su producción intelectual. Como lo expresó un teólogo norteamericano, él vivió en el punto donde se interceptan la teoría y la praxis, donde la razón y la compasión se dan de la mano (Burke, 2000, p. 214). La totalidad de su vida y de su pensamiento adquirió a la vez la triple característica de inteligencia, compasión y servicio. En la medida que su producción intelectual no se limitó simplemente a hacer avanzar el logos, su filosofía y su teología estaban inspiradas por un intellectus misericordiae (como lo afirma Jon Sobrino), un intelecto compasivo. Pero como esa compasión debe ser historizada según sea la opresión que se debe erradicar, se debe hablar con mayor precisión de la filosofía (y de la teología) de Ellacuría como intellectus iustitiae, intellectus liberationis. Y por ello le era esencial a su pensamiento relacionar el intellectus con una praxis liberadora, como quiera que se formulara ésta (Sobrino, 1995, pp. 20-21).

Esto nos remite a la idea de filosofía que Ellacuría empezó a forjar desde sus años juveniles, en la década de los cincuenta, como escolar jesuita. Ellacuría sostenía en esa época que la filosofía como forma de vida significa adoptar la actitud radical del filosofar mismo y extenderla a la propia vida. En este sentido, la filosofía no es un mero ejercicio intelectual extrínseco a la vida del filósofo y a los problemas que enfrenta vitalmente en su situación. Esto lleva a que el filósofo se involucre existencialmente con la develación y revelación de la realidad que se le hace presente como problema en su propia experiencia biográfica e histórica.

Pues bien, esta realidad se le presentaba a Ellacuría en los últimos años de su vida con una radical negatividad, como una realidad dominada por un mal común, "un mal que definiéndose negativamente como no realidad, es el que aniquila y hace malas todas las cosas, pero que en razón de la víctima negada puede dar paso a una vida nueva, que tiene caracteres de creación" (Ellacuría, 1991c, p. 64). Y si esto es así, la liberación ya no es un puro tema externo a la reflexión del filósofo y en torno al cual construye argumentos para fundamentar su necesidad o su bondad, sino algo que atañe a su propia vida, y que asume, por tanto, como un principio constitutivo de su propia existencia. Por ello se puede decir que en el caso de Ellacuría, como en el de Sócrates, la filosofía no solamente fue una tarea intelectual sino fundamentalmente una forma de vida. $\mathrm{O}$ como lo expresa el mismo Ellacuría (1991c): 
Lo esencial es dedicarse filosóficamente a la liberación más integral y acomodada posible de nuestros pueblos y nuestras personas; la constitución de la filosofía vendrá entonces por añadidura. Aquí también la cruz puede convertirse en vida (p. 62).

Consecuente con esta postura, Ellacuría optó por vivir en el mundo de los desposeídos y los crucificados de la tierra, se ubicó conscientemente en el lugar de la realidad histórica donde no había posibilitación sino opresión, que es el lugar de las víctimas despojadas de toda figura humana, y por él dio su vida. En este sentido, no solo su filosofía y su teología, sino también su praxis y su destino dan mucho que pensar y pueden ser también para todos y todas una exhortación para actuar.

\section{5 A modo de conclusión}

Ignacio Ellacuría dedicó su vida y su pensamiento a interpretar los "signos de los tiempos" para conocer lo que ocurre en realidad, lo que fluye en el dinamismo histórico, y evitar las catástrofes humanas que se nos avecinan, orientado por un horizonte de plena positividad, ya sea la utopía o el reinado de Dios, como dirían los académicos y los teólogos respectivamente.

La vida práctica de Ellacuría fue impresionante. "Filósofo de nacimiento", teólogo por su dimensión cristiana que, con su touch filosófico, lo llevó a ser el teólogo de su generación; conocedor de la política por necesidad histórica y por solidaridad y mediador entre los grupos enfrentados en la guerra civil de El Salvador.

Pero también Ellacuría fue un mártir por excelencia, es decir un "testigo" de su tiempo, con gran fervor y amor cristiano, que hacía del mordaz y crítico Ellacuría, un aprendiz de brujo en una turbulenta realidad donde aprendía con una inmensa humildad.

A los 26 años de su asesinato, la obra de Ellacuría, la vida de Ellacuría, el ejemplo de Ellacuría, el legado inmenso de la compasión de Ellacuría, la fuerza de su mensaje de cara al futuro, debe ser retomado y continuado en la actualidad, a la luz de las nuevas realidades y de las nuevas situaciones que se han configurado en esta segunda década del siglo XXI en El Salvador, en Centroamérica y en el mundo. 


\section{Referencias}

- Burke, K. F. (2000). The Ground Beneath the Cross. The theology of Ignacio Ellacuría. Washington, D. C.: Georgetown University Press.

- Doggett, M. (1994). Una muerte anunciada. San Salvador: UCA Editores.

- Ellacuría, I. Utopía y profetismo desde América Latina. Revista Latinoamericana de Teología, 17, 141-184.

- Ellacuría, I. (1990/1991). Filosofía de la realidad histórica. San Salvador: UCA editores; Madrid: Trotta, 1991.

- Ellacuría, I. (1991a). Veinte años de historia en El Salvador (1969-1989). Escritos políticos, tres tomos. San Salvador: UCA Editores.

- Ellacuría, I. (1991b). Universidad y política. En política. En Veinte años de historia en El Salvador (1969-1989). Escritos políticos, tomo I (pp. 17-45). San Salvador: UCA Editores.

- Ellacuría, I. (1991c). Función liberadora de la filosofía. En Veinte años de historia en El Salvador (1969-1989). Escritos políticos, tomo I (pp. 93-121). San Salvador: UCA Editores.

- Ellacuría, I. (1991d). Factores endógenos del conflicto centroamericano: crisis económica y desequilibrios sociales. En Veinte años de historia en El Salvador (1969-1989). Escritos políticos, tomo I (pp. 139-172). San Salvador: UCA Editores.

- Ellacuría, I. (1992). Subdesarrollo y derechos humanos. Revista Latinoamericana de Teología, 25, 3-22.

- Ellacuría, I. (1999). Diez años después, ¿es posible una universidad distinta? En Escritos universitarios (pp. 49-92). San Salvador: UCA Editores

- Ellacuría, I. (2001a). Filosofía, ¿para qué? En Escritos filosóficos, Tomo III (pp. 115-131). San Salvador: UCA Editores.

- Ellacuría, I. (2001b). El mal común y los derechos humanos. En Escritos filosóficos, Tomo III (pp. 447-450). San Salvador: UCA Editores.

- Ellacuría, I. (2009a). Curso de Ética. En Cursos universitarios (pp. 253-280). San Salvador: UCA Editores.

- Ellacuría, I. (2009b). El sujeto de la historia. En Cursos universitarios, (pp. 281-326). San Salvador: UCA Editores.

- Samour, H. (2003). Voluntad de liberación. La filosofía de Ignacio Ellacuría. Granada: Comares, Granada. 
- Samour, H. (2013). El mal común y la crítica de la civilización del capital en Ignacio Ellacuría. Estudios Centroamericanos (ECA), 732, 7-18.

- Senent de Frutos, J. A. (1998). Ellacuría y los derechos humanos. Bilbao: Desclée de Brouwer.

- Sobrino, J. (1995). Ignacio Ellacuría: la inteligencia al servicio del pueblo crucificado. En Para una filosofía liberadora (Actas del Primer Encuentro Mesoamericano de Filosofía, San Salvador, 11-15 de noviembre de 1994, pp. 13-29). San Salvador: UCA Editores.

- Whitfield, T. (1998). Pagando el precio. San Salvador: UCA Editores.

\section{Notas}

1 Ponencia inaugural del XI Congreso Internacional de la Cátedra Latinoamericana Ignacio Ellacuría, celebrado en la Universidad Loyola de Andalucía, Sevilla, España, del 25 al 27 de noviembre de 2015.

2 Es claro que, históricamente, las universidades latinoamericanas han propendido a caer en una de esas dos formas falsas de politización. Por un lado, universidades dedicadas a favorecer, por su orientación profesionalizante, a los más privilegiados en la escala social, pretendiendo una presunta cientificidad neutra. Por otro, universidades que han ido en busca de una acción política inmediata para lo cual no están instrumentalmente preparadas y para lo cual no han contado con el poder debido, con menoscabo evidente de la preparación científica y técnica.

3 En las prácticas políticas hay supuestos ideológicos indispensables, que son realmente operativos, sobre todo para que los integrantes de grupos y de movimientos populares o sociales sigan los lineamientos de sus dirigentes, pero también para que la acción sea fortalecida por la comprensión de su sentido o significado.

4 Ellacuría afirmaba que el problema de filosofía y libertad toca a fondo el problema fundamental del quehacer filosófico, que aunque abstractamente pudiera definirse como búsqueda de la verdad, difícilmente podría quedar reducido a una mera búsqueda de la verdad por la verdad. En un contexto histórico marcado por la injusticia, la opresión y aun la represión, es necesario precisar la función liberadora que le corresponde a la filosofía aquí y ahora para, que sin dejar de ser filosofía, sea realmente eficaz a la hora de liberar a la totalidad de la cultura y a la totalidad de las estructuras sociales, dentro de las cuales las personas tienen que autorrealizarse libremente. 